\title{
Quantification of the abundance and diversity of predatory spiders in rice ecosystem of Rajendranagar, Telangana, India
}

\author{
G. Anitha ${ }^{1^{*}}$ and J.Vijay ${ }^{2}$ \\ ${ }^{1 *}$ All India Coordinated Project on Biological Control, Rajendranagar, Hyderabad - 500030, Telangana, INDIA \\ ${ }^{*}$ Present address \\ *Department. of Entomology, College of Agriculture, Rajendranagar, Hyderabad - 500 030, Telangana, INDIA \\ ${ }^{2}$ Department off Agronomy, College of Agriculture, Rajendranagar, Hyderabad - 500 030, Telangana, INDIA \\ "Corresponding author. E-mail: gorthianitha@gmail.com
}

Received: September 2, 2015; Revised received: February 27, 2016; Accepted: June 5, 2016

\begin{abstract}
The effective prey searching ability and polyphagy of spiders makes them important predators of crop pests. 19 species of spiders have been recorded in rice ecosystem (Rajeswaran et al., 2005). There is now a growing need to conserve all species and not only the large vertebrates (Samways, 1990) and contribute to the natural biological process. However, literature pertaining to their abundance and diversity in rice crop in Rajendranagar area is scant. Hence, the $\mathrm{p}$ resent study was conducted to understand their abundance and diversity. Spider samples were collected from rice fields of Rajendranagar in kharif and rabi seasons of 2011-12 and 2012-13. A total of 2,094 individuals collected in kharif represented eight families with a density of $12.48 / \mathrm{sq} . \mathrm{m}$. Members of Tetragnathidae were recorded most abundantly in kharif (46.32\% of the Arachnid population) followed by Lycosids $(26.22 \%)$. In rabi 1,095 spiders of seven families were collected with a density of $6.38 / \mathrm{sq} . \mathrm{m}$. Tetragnathidae and Lycosidae were the most abundantly found species in rabi also comprising $27.85 \%$ and $26.12 \%$ of Arachnid population respectively. Study of guild composition was also carried out. A t-test between indices of richness, diversity, effective no.of species and species evenness of kharif and rabi seasons revealed that there were no significant differences with respect to these parameters $(p>0.05)$ indicating that spider diversity of rice in Rajendranagar was more or less same between kharif and rabi seasons. This is the first study on the spider diversity of rice ecosystem of Rajendranagar, Hyderabad, India.
\end{abstract}

Keywords: Density, Diversity, Guild composition, Spiders, Species evenness, Species richness

\section{INTRODUCTION}

Spiders are found everywhere worldwide, and have become established in every habitat with the exceptions of air and sea colonization. Their prey searching ability and polyphagy makes them effective predators of crop pests. They are obligate carnivores and hold the unique position of being the only class of arthropods which is entirely predatory in nature. Predation contributes significantly towards preventing excessive increase of insect populations (Sudhikumar, 2007). Nearly 350 species of spiders are reported to occur in the rice ecosystem in south and South East Asia (Barrion and Litsinger, 1995).Usually, species richness and abundance of predator populations may be greater than those of the pest populations, when little or no insecticides are used (Way and Heong, 1994). Research on spider diversity in agroecosystems is highly valuable, both to observe the effect they have on herbivorous pests (Maloney et al., 2003) and to understand how profound changes on the environment affect spider colonisation (Öberg, 2007). Thus, it is relevant to evaluate the spider fauna in the agroecosystem surroundings as was done for the rice crop (Murata, 1995;
Barrion, 1999; Liu et al., 2003). 19 species in rice ecosystem, 13 species in maize, 16 species in soybean, 18 species in oil seeds, 21 species in cotton, 57 species in sugarcane, 13 species in vegetables, 11 species in fruit crops and 26 species in coconut have been recorded (Rajeswaran et al., 2005). But, such information about rice ecosystem in Rajendranagar is practically nonexistent. Hence, a study was conducted to quantify the abundance and diversity of spiders in rice ecosystem of Rajendranagar, Hyderabad.

\section{MATERIALS AND METHODS}

Surveys were conducted in kharif and rabi seasons for two years i.e. 2011-12 and 2012-13 in five rice fields of seed production division in the College Farm, Rajendranagar, Hyderabad. Each field measured 400 sq.m. and population in five quadrats of $1 \mathrm{sq} . \mathrm{m}$. were recorded by visual search method at ten-day interval from 15 days after transplantation (DAT) to $120 \mathrm{DAT}$. Observations were recorded from five such rice fields. Representative samples were collected, washed in distilled water and preserved in $70 \%$ alcohol for identification. Identification upto genus level was done based 
on keys given by Barrion and Litsinger (1995). The following aspects were studied to understand spider abundance, density, species richness, species diversity, effective number of species and species evenness.

Abundance and density: The total number of spiders observed in each count was pooled up season wise for two years. They were classified into families and the number of spiders under each family was recorded. Percentage of individuals under each family was computed as fraction of the total number of spiders recorded. They were graded into guilds (Barrion and Litsinger, 1995) and guild composition for both the seasons was worked out. Density of spiders was worked out using the formula.

Density $=\underline{\text { Total number of spiders recorded }}$

Number of quadrats observed

Species richness: Margelef Species Richness Index was used to understand species richness and this was calculated using the following formula.

Margelef's species richness index $=(\mathrm{S}-1) / \mathrm{Ln}(\mathrm{N})$

Where,

$\mathrm{S}=$ total number of species

$\mathrm{N}=$ total number of individuals in the sample

$\mathrm{Ln}=$ natural logarithm

Species diversity: Species diversity was studied using

Table 1. Details of the genera observed.

\begin{tabular}{lll}
\hline S.N. & Spider family & Genus \\
\hline 1. & Tetragnathidae & Tetragnatha virescens \\
2. & Lycosidae & Lycosa pseudoannulata \\
3. & Oxyopidae & Oxyopes javanus \\
4. & Salticidae & Bianor maculatus \\
5. & Thomisidae & Thomisus \\
6. & Clubionidae & Clubiona \\
7. & Araneidae & Neoscona \\
8. & Linyphiidae & Argiope catanulata \\
\hline
\end{tabular}

indices like Shannon-Wiener index, True Diversity, Berger Parker Index (B) Simpson Index (D) and Gini-Simpson Index $(1-\lambda)$ and these were calculated using the BPMSG Online calculator (Goepel, 2013).

Effective number of species: This was calculated using the formula.

ENS $=$ Exponential $\left(\mathrm{H}^{\prime}\right)$

where, $\mathrm{H}^{\prime}=$ Shannon-Wiener index

Species evenness: The Pielou's Evenness Index (E) (Pielou, 1966) was used to understand species evenness. This was calculated using the formula.

$\mathrm{E}=\mathrm{H}^{\prime} / \mathrm{Ln} \mathrm{S}$

where,

$$
\begin{aligned}
& \mathrm{H}^{\prime}=\text { Shannon }- \text { Wiener diversity index } \\
& \mathrm{S}=\text { total number of species in the sample } \\
& \mathrm{Ln}=\text { Natural logarithm }
\end{aligned}
$$

After calculation of the above parameters, a t-test was conducted to compare the indices of kharif and rabi seasons and understand the impact of seasons on the diversity of spiders.

\section{RESULTS AND DISCUSSION}

Abundance and density: A total of 2,094 individuals were collected in kharif and 1,095 in rabi. In kharif, representatives of eight families of spiders were recorded viz., Tetragnathidae, Clubionidae, Oxyopidae, Araneidae, Thomisidae, Salticidae and Lyniphiidae (Table 1). The order of abundance was found to be Tetragnathidae $>$ Lycosidae $>$ Oxyopidae $>$ Salticidae $>$ Araneidae $>$ Lyniphiidae $>$ Thomisidae $>$ Clubionidae (Table1). In rabi, spiders of seven families were recorded viz., Tetragnathidae, Lycosidae, Clubionidae, Oxyopidae, Thomisidae, Araneidae and Lyniphiidae. The order of abundance was found to be Lycosidae > Tetragnathidae $>$ Clubionidae $>$ Thomisidae $>$ Lyni-

\begin{tabular}{|c|c|c|c|c|c|c|c|c|c|}
\hline Season & $\begin{array}{l}\text { No. of } \\
\text { species }\end{array}$ & $\begin{array}{l}\text { Effective } \\
\text { no. of } \\
\text { species } \\
\text { (ENS) }\end{array}$ & $\begin{array}{l}\text { Margelef } \\
\text { species } \\
\text { richness } \\
\text { index }\end{array}$ & $\begin{array}{l}\text { Species } \\
\text { diversity } \\
\text { (Shannon- } \\
\text { Wiener } \\
\text { Index) H }\end{array}$ & $\begin{array}{l}\text { True } \\
\text { diversity }\end{array}$ & $\begin{array}{l}\text { Berger } \\
\text { Parker } \\
\text { Index } \\
\text { (B) }\end{array}$ & $\begin{array}{l}\text { Simpson } \\
\text { Index } \\
\text { (D) }\end{array}$ & $\begin{array}{l}\text { Gini- } \\
\text { Simpson } \\
\text { Index } \\
(1-\lambda)\end{array}$ & $\begin{array}{l}\text { Pielou's } \\
\text { species } \\
\text { evenness } \\
\text { Index (J') }\end{array}$ \\
\hline \multirow{2}{*}{$\begin{array}{l}\text { Kharif } \\
\text { Rabi }\end{array}$} & 9 & 4.62 & 1.00 & 1.53 & 3.3 & $46.30 \%$ & 0.29 & $70.10 \%$ & 0.69 \\
\hline & 8 & 6.11 & 1.004 & 1.81 & 5.2 & $27.90 \%$ & 0.19 & 80.70 & 0.76 \\
\hline
\end{tabular}
phiidae > Araneidae > Oxyopidae. Sudhikumar (2007)

Table 2. Diversity indices of spiders in Rajendranagar in kharif and rabi of 2011-12 and 2012-13.

Kharif

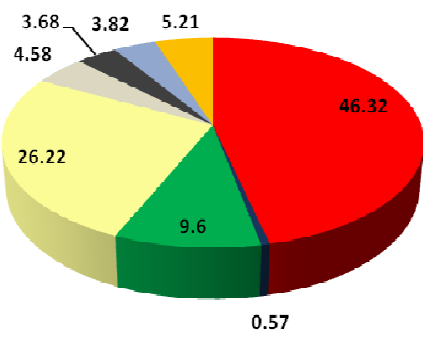

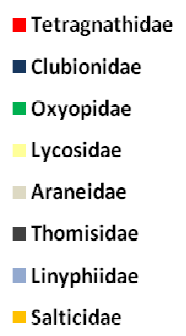

Fig. 1. Composition of spider population in kharif. rabi

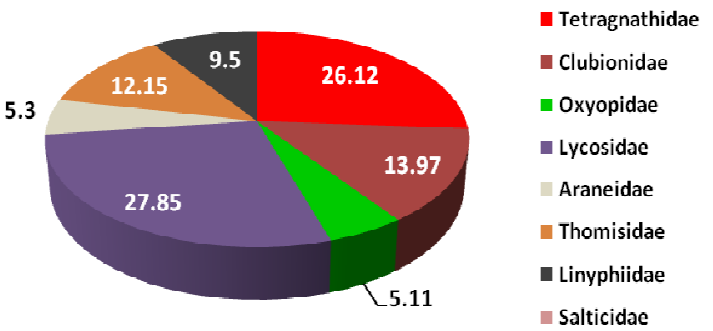

Fig. 2. Family-wise abundance levels in rabi. 


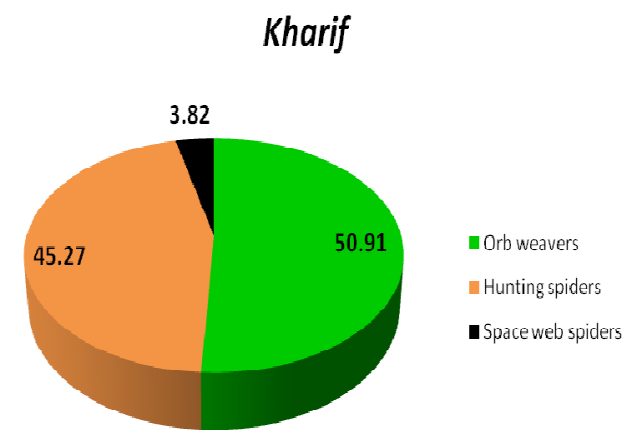

Fig.3. Guild composition of spiders in rice in kharif.

collected more number of individuals during kharif season $(17,7171)$ than rabi season. Jayakumar and Sankari (2010) reported a total of 5 species of spiders from 5 families videlicet, Lycosa pseudoannulata Boes and Stand (Lycosidae), Callitrichia formosana (Linyphidae), Tetragnatha javanas Thorell (Tetragnathidae), Argiope catenulate Doleschall (Araneidae) and Plexippus species (Salticidae) from six different treatments of rice crop in Adathurai, Tamil Nadu. Rajna and Chander (2013) recorded a diversity of six spider families viz., Oxyopidae, Lycosidae, Tetragnathidae, Araneidae, Thomisidae and Salticidae in rice in New Delhi. Shunmugavelu and Karthikeyani (2010) recorded spiders belonging to seven families viz., Araneidae, Pholcidae, Lycosidae, Tetragnathidae, Salticidae, Oxyopidae, Thomisidae from Theni dt., Tamil Nadu. Vijaykumar and Patil (2004) recorded members of eight families viz., Lycosidae, Tetragnathidae, Salticidae, Araneidae, Clubionidae, Eresidae, Thomisidae and Pisauridae from rice ecosystems of Karnataka. Khan (2011) collected a total of 1,155 individuals of thirteen families from temperate rice ecosystem of Kashmir. Rodrigues et al. (2009) reported a total of 2,717 spiders, distributed among 15 families from southern Brazil. Density of spiders was found to be 12.48/sq.m in kharif and 6.38/sq.m in rabi. Shivamurthappa (1993) recorded a maximum of 8.15 spiders per hill during first fortnight of November, peaked with 2,96,000 spiders/ha on 10th July and in late sown fields they peaked with $3,45,000 /$ ha on 11 th September. Khan (2011) registered densities varying with crop growth stages, but highest was 15,016/sq.m. Rodrigues et al. (2009) recorded an average of 19.98 ( \pm 5.14 s.e.) spiders per transect, $30.86 \pm 4.58$ for grassland, it was $13.5 \pm 2.26$ for rice and $22.09 \pm 2.38$ for forest edge. Among different families recorded, members of Tetragnathidae were observed to be most abundant in kharif (46.32\% of the Arachnid population) followed by Lycosids (26.22\%). Next were Oxyopids $(9.6 \%)$ followed by Salticids $(5.21 \%)$. All the families were represented by only one genus (Table 1) except Araneidae, which was represented by Neoscona and Argiope and they constituted $4.58 \%$. Thomisidae made
Rabi

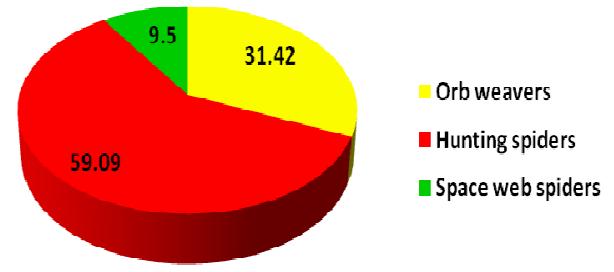

Fig.4. Guild composition of spiders in rice in rabi.

up to only $3.68 \%$ and Linyphiidae upto $3.82 \%$. Clubionids were rarely found $(0.57 \%$ of the population). Data recorded in rabi revealed that members of Tetragnathidae and Lycosidae were the most abundantly found species comprising $27.85 \%$ and $26.12 \%$ of Arachnid population respectively. Clubionidae and Thomisidae were more abundant in rabi $(13.97 \%$ and $12.51 \%$ respectively) than kharif. While Linyphiidae made upto $9.5 \%$ of the spider population, Araneidae constituted $5.3 \%$. Oxyopids were more prolific in kharif and constituted only $5.11 \%$. It was found that Tetragnathidae, Oxyopidae and Salticidae were more abundant in kharif compared to rabi, while Clubionidae, Thomisidae and Linyphiidae were prolific in rabi than kharif. However, there was not much difference in the abundance of Lycosidae and Araneidae between kharif and rabi. A survey by Gupta et al. (1986) in Andhra Pradesh revealed the relative abundance of spiders as Tetragnathidae (47\% of species), Araneidae (20\%). Lycosidae (16\%), Thomisidae (10\%), Clubionidae (4\%) and Oxyopidae (2\%). Samiayyan and Chandrasekharan. (1998) recorded higher populations of Lycosa pseudoannulata and Callitrichia formosana populations from 42-113 days after transplantation in the early stages of the crop. Khan (2006) reported Lycosidae to comprise $16.74 \%$ of the hunting spider population, Oxyopidae $(5.37 \%)$, Salticidae (4.49\%), Clubionidae $(4.82 \%)$ and Thomisidae $(3.27 \%)$ of population of ambushing spiders, while Araneidae (6.38\%), Tetragnathidae (8.05\%), Theridae $(0.09 \%)$ comprised the web builders in six rice growing districts of Uttar Pradesh.

Guild composition: Spiders observed were classified into guilds after Uetz (1999). Study on guild composition of spiders revealed that orb-weavers dominated the scenario in kharif (50.91\% of the population) and hunting spiders dominated $(50.09 \%)$ in rabi. Hunting spiders constituted $45.27 \%$ of population in kharif and orbweavers made upto $31.42 \%$ population in rabi. Spaceweb spiders were less abundant and accounted for $3.82 \%$ of population in kharif and $9.5 \%$ in rabi. Results of t-test revealed that species richness, effective no.of species, evenness and diversity were compa- 
rable between kharif and rabi and there were no significant differences with respect to all the parameters observed ( $p>0.05)$ (Table 2).

Species richness: The no.of species recorded was 9 in kharif and 8 in rabi. Furthermore, Margelef species evenness was similar (1.00) in both the seasons indicating that species evenness was very much similar in both the seasons.

Species diversity: No significant difference was observed in the Shannon Wiener Index $\left(\mathrm{H}^{\prime}\right)$ or species diversity between the seasons (1.53 in kharif and 1.81 in rabi resp.). Moreover, true diversity didn't differ significantly (3.3 and 5.2 respectively) too. Likewise, Simpson Index (D) which quantifies the biodiversity was found to be 0.29 in kharif and 0.19 in rabi indicating lesser differences between the seasons. Similarly, Berger-Parker index which is given by the mean fraction of total sampled individuals contributed by the most abundant species was comparable between kharif and rabi since the level of abundance of some species was not very different between kharif and rabi. GiniSimpson Index in kharif was comparable to that in rabi indicating that the probability of two individuals selected randomly from a sample belonging to different species was almost similar. Sudhikumar (2007) recorded a Shannon index of 3.31 \pm 0.04 in kharif season and 3.19 \pm 0.02 in rabi in Kuttanad district of Kerala. Goswami et al. (2015) found that Shannon diversity varied from 1.73-2.17, while Simpson index was between 0.13-0.18, Margelef richness index was found to be between 1.15-1.86, while Evenness index ranged between $0.69-0.72$ at different growth stages of rice crop in three districts of Bihar. Ghafoor and Mahmood (2011) compared the Araneid diversity of Gujranwala with that of Kamoki area in Pakistan and found that Margelef index ranged between 28.14-29.43, Shannon Diversity index was 2.67-2.69, Pielou's evenness index 0.91-0.92, Simpson's Diversity index was 0.93. Similarly, Zhang et al. (2013) observed no significant differences $(p<0.05)$ between the arthropod communities of the early and late season rice crops with respect to the Shannon-Weaver diversity index $(1.01 \pm 0.14$ to $1.14 \pm, 0.08)$, the Pielou evenness index $(0.63 \pm 0.09$ to $0.71 \pm 0.05)$ and the Simpson dominance index $(0.26 \pm 0.09$ to $0.15 \pm 0.03)$ in Guangdong Province of China.

Effective no. of species: In kharif was 4.62 while in rabi it was 6.11 . Since $p<0.05$, it could be inferred that there was no significant difference in the number of spider genera (species) between kharif and rabi. There was not much change in the diversity of spiders between the seasons. However, Saikia and Baruah (2008) reported that species were richer in Sali (winter rice) than Boro (summer rice)

Species evenness: Pielou's species evenness in kharif (0.69) was not significantly different from that in rabi (0.76). Evenness measures how similar the abundance of different species are and a low value of Shannon Weiner Index, indicates that the species are not evenly distributed in kharif season with Tetragnathids being the most abundant ones and Clubionids the rarest ones. In rabi, the evenness was little higher (though not significantly since $\mathrm{p}>0.05$ ) as Tetragnathids and Lycosids were of equal abundance and Araneids were the rarest family recorded.

\section{Conclusion}

Studies on abundance and diversity of spiders spanning the crop period is a pre-requisite to understand their bioecology and habitat and to design crop pest management tactics in ways so as not to disrupt the huge scope of natural control offered by these key predators specially in organically grown rice. A density of 6.38-12.48 spiders/ sq.m. and a diversity of nine genera, each with varied food preferences ensured superior natural control as was observed in the present study. There were no significant differences in the abundance, diversity, richness and evenness of the spider guilds of kharif and rabi rice ecosystem in Rajendranagar. This could depend on factors like pest situation, prevailing weather factors, agronomic practices followed etc. Application of organic fertilizers (manures) enhances soil living organisms and many spider species utilize such prey in addition to above-ground herbivorous prey. Information generated from the present study could facilitate preparation of checklists of spiders to be used by taxonomists.

\section{REFERENCES}

Barrion, A.T. and Litsinger, T.E. (1995). Riceland Spiders of South and Southeast Asia. Cab. Int., Wallingford, U.K.

Barrion, A.T. (1999). Guild structure, diversity and relative abundance of spiders in selected non-rice habitats and irrigated rice fields in San Juan, Batangas, Philippines. Philippine Entomologist, 13 (2): 129-157.

Ghafoor, A. and Mahmood, A. (2011). Population Dynamics Of The Araneid Fauna From District Gujranwala, Pakistan. The Journal of Animal \& Plant Sciences, 21 (4): 812-816.

Goepel K.D. (2012). AHP Excel template, Oct. 2012. Business Performance Management . http://bpmsg.com retrieved on 26 April,2015

Goswami, T.N., Kumari, K. and Kole, A.B. (2015). Quantitative Estimation of spider fauna in rice ecosystem of Zone IIIA in Bihar. Environment and Ecology, 33 (2) : 783-785.

Gupta, M., Rao, P. and Pawar, A.D. (1986) Survey of the predatory spider fauna from rice agro ecosystems. Indian Journal of Plant Protection, 14 (2): 19-21.

Khan, A.A. (2006). Relative abundance of spider fauna in rice ecosystem. SAARC Journal of Agriculture, 4: 159166.

Khan, A.A. (2011). Spider fauna on temperate rice in Kashmir. Oryza., 48 (2) : 147-153.

Liu, Y.F. Gu, D.X. and Zhang, G.R. (2003). Studies on the diversity of spiders community in paddy ecosystems in Guangdong. Acta Arachnologica Sinica., 12 (1): 27-31.

Maloney, D., Drummond, F.A. and Alord, R. (2003). Spider predation in Agroecosystems: Can spiders effectively control pest population. MAFES Tech. Bull., 190: 1-32.

Murata, K. (1995). The interaction between spiders and prey insects under the sustainable cultivation - influence of the paddy field spiders and the prey insects. Acta Arachnol., 44 : 83-96 
Öberg, S. (2007). Diversity of spiders after spring sowing influence of farming system and habitat type. Journal of Applied Entomology, 131 (8): 524-531.

Pielou, E.C. (1966). The measurement of diversity in different type of biological collection, Journal of Theoretical Biology, 13: 31-144.

Rajna, S. and Subhash, C. (2013). Predator diversity vis-ávis pest incidence in rice ecosystem. Indian Journal of Entomology, 75 (2):104-108.

Rodrigues, E.N.L., Mendonça, M.D.S. Jr. and Ricardo O.T.T. (2009). Spider diversity in a rice agroecosystem and adjacent areas in southern Brazil. Revista Colombiana de Entomología, 35 (1): 89-97.

Jayakumar, S. and Sankari, A. (2010). Spider population and their predatory efficiency in different rice establishment techniques in Aduthurai, Tamil Nadu. Journal of Biopesticides, 3 (1) : 020 - 027.

Rajeswaran, J., Duraimurugan, P. and Shanmugam, P.S. (2005). Role of spiders in agriculture and horticulture ecosystem. Food, Agriculture and Environment, 3 (3\&4): 147-152.

Saikia, P. and Baruah, M. (2008). Spider Fauna of rice ecosystem in Northern Assam. J. Appl. Zool. Res., 19 (2): 163 166.

Samiayyan, K. and Chandrasekharan, B. (1998). Influence of botanicals on the spider populations of rice. Madras $J$. Agric., 85: 479-480.

Samways, M.J. (1990). Insect conservation ethics. Environmental Conservation, 17 : 7-8.
Shivamurthappa, (1993). Management of brown plant hopper, Nilaparvata lugens (Stal) by cultural practices and insecticides and investigation on biotypes in Karnataka. $\mathrm{Ph} . \mathrm{D}$. Thesis, University of Agricultural Sciences, Bangalore, p.217.

Shunmugavelu, M. and Karthikeyani, R. (2010). Diversity and Distribution of the Spiders (Araneae) in the Paddy Ecosystem of Kumbakarai Falls, Tamil Nadu, South India. Insect Environment, 16 (1): 27-29.

Sudhikumar, A.V. (2007). Studies on the taxonomy and bionomics of some predacious spiders on insect pests of rice agroecosystem in Kuttanad, Kerala. Ph. D. thesis submitted to Mahatma Gandhi University, Kottayam, Kerala, India. $124 \mathrm{pp}$.

Uetz, G.W., Halaj, J., Cady, A.B. (1999). Guild structure of spiders in major grops. The J. of Arachnol., 27: 270-280.

Vijaykumar and Patil, B.V. (2004). Spider Fauna of Paddy ecosystem in Selected Areas of Tungabhadra Project in Karnataka. Karnataka J. Agri. Sci., 17 (3): (584-585).

Way, M.J. and Heong, K.L. (1994). The role of biodiversity in the dynamics and management of insect pests of tropical irrigated rice: a review. Bull. Entomol. Res., 84: $567-587$

Zhang. J., Zheng,X., Jian, H., Qin, X., Yuan, F. and Zhang, R. (2013). Arthropod biodiversity and community structures of organic rice ecosystems in Guangdong Province, China. Fla. Entomol., 96 (1): 1-9. 